\title{
INTRODUCTION: TOWARD AN ANTHROPOLOGY OF AFFECT AND EVOCATIVE ETHNOGRAPHY
}

\section{Ian Skoggard}

Human Relations Area Files, Yale University

ian.skoggard@yale.edu

Alisse Waterston

John Jay College, City University of New York

awaterston@jjay.cuny.edu

\begin{abstract}
A growing interest in affect holds much promise for anthropology by providing a new frame to examine and articulate subjective and intersubjective states, which are key parts of human consciousness and behavior. Affect has its roots in the social, an observation that did not go unnoticed by Durkheim and since then kept in view by those social scientists interested in the emotions, feelings, and subjectivity. However, the challenge for ethnographers has always been to articulate in words and conceptualize theoretically what is only felt and sensed. What we are calling "evocative ethnography" is an ethnography that meets this challenge to make room for, and hold onto, feelings and affect in its description and explanation. The papers in this special issue accomplish that, as well as, provide some anthropological insights into affect theory.
\end{abstract}

KEYWORDS: affect, affect theory, anthropology of emotions, subjectivity

The very act of congregating is a powerful stimulant. Once the individuals are gathered together, a sort of electricity is generated from their closeness and quickly launches them to an extraordinary height of exaltation. Every emotion expressed resonates without interference in consciousness that are wide open to external impressions, each one 
echoing the others. The initial impulse is thereby amplified each time it is echoed, like an avalanche that grows as it goes along. And since passions so heated and so free from all control cannot help but spill over, from every side there are nothing but wild movements, shouts, downright howls, and deafening noises of all kinds that further intensify the state they are expressing. - Emile Durkheim, The Elementary Forms of Religious Life (1976 [1915]: 217-218)

The "we" incites participation and takes on a life of its own, even reflecting its own presence. It's a thing that happens when e-mails with joking commentary show up in your in-box and you pass them on for some reason. Or when intimate public slogans float into a collective mode of address: "Know what I'm sayin'?" "That's just wrong," "I don't THINK so," That's what I am talkin' about," "I hear you," "It's all good." Or when bumper stickers talk back to each other as if they can't help it: "Shit happens," "Magic happens," "My child is an honor student," "My child beat up your honor student," "Just say no," "Just do it," "Vote Bush," "I voted for Bush and got Dick," "Bush is a punk ass chump,” “Bush bin Lyin'.” - Kathleen Stewart, Ordinary Affects (2007:28)

These two descriptions of aspects of "the social” are written nearly one hundred years apart (Brown 2014). Emile Durkheim’s quote is his famous description of the corroboree ritual of the Warramunga, which was the inspiration for his approach to the sociology of religion. It is an enthusiastic testament to the subjective power of the collective moment, which further confirmed the concept of the social as a unique realm of study separate from the political and economic. Kathleen Stewart's quote is of another sociality, one more tame and domesticated, but nevertheless a testimony to the subjective "we-ness" that lies at the heart of the social. Both authors acknowledge the existence and uniqueness of an inter-subjective realm of the social, yet they react to it differently. For the sake of science, Durkheim distanced himself from the “powerful stimulant”, “electricity”, and “extraordinary height of exaltation” of the congregating throng, dismissing it as "primitive" and "not fully subordinate to reason and will." In place of the word "primitive”, Durkheim might very well have invoked the terms "feminine”, “primordial”, “tribal”, “childish”, or “ephemeral”, reflecting the intellectual bias of his time that eschewed anything associated with the emotional. This dismissal of feelings associated with human sociality would un-anchor the new science of sociology from the sensory of the inter- 
subjective realm, making it susceptible to abstraction, reification, and fetishization, and opening it up to reductive explanations of the social (Csordas 1990: 33).

Stewart takes a different position. She accepts the "we-ness" as is and does not turn her back on it, keeping it present. Her position represents the so-called "affective turn" in the social sciences and rise of a new theoretical frame that acknowledges and analytically tries to accommodate the power of feelings, sentimentality, intimacies, and emotion in the public realm. Affect theory has the promise to bridge the conceptual dualisms that have plagued the social sciences, such as those between mind and body, self and other, private and public, personal and political, and agency and structure (Lutz and White 1986: 406-409). However, the danger in trying to grasp intellectually what is fundamentally felt and sensed might reduce affect to an empty shell of a concept following the same fate as the "social", a limited concept that remains vague (Brown 2014: 23). To avoid that fate, affect theory must come to life by means of an integration of abstraction and illustration. The challenge is to write evocatively about culture in a way that emotions and feelings of living, socially situated subjects are conveyed to the reader, what might be called "evocative ethnography" (Stoller 2005; 2007).

Feelings matter. They are an integral part of human consciousness and behavior. Human beings are as much feeling creatures as they are thinking ones. Hunches and intuition play a major role in reasoning and passion provides impetus for action. The neuroscientist Antonio Damasio (1994) argues that the capacity to feel is a necessary component of rational decision-making. Early on, the social psychologist Robert Zajonc (1980) postulated that feelings emerge prior to and independently of cognition (see also Massumi 1995). Affective neuroscience attempts to identify different parts of the brain that are associated with emotions and cognition (Dalgleish 2004), and neuro-biology seeks to understand "affective systems" that influence 
behavior (Charland 2001, 151). Anthropologist Walter Goldschmidt (2006) sees affect as a missing piece in understanding human behavior and evolution. He regards ritual as a "language of sentiment" that extends maternal and sexual feelings outward to form wider social attachments, a position long recognized by anthropologists examining the affective or "felt" component of rituals, albeit through a structural functionalist lens (Leavitt 1996: 526). Gender and Queer Studies scholar Sara Ahmed (2004) understands feelings as a pre-linguistic, precognitive, and inter-subjective medium, which circulates through the social body, mediating between the psychic and social, and the collective and individual, working to bind and separate subjects. Lauren Berlant (2008) calls for a popular feminism based on a collective affect that does not shun sentimentality and is separate from but ultimately inspires an emancipatory politics. In general, anthropologists have recognized the importance of emotions in culture (Lutz and White 1986; Leavitt 1996; Luhrmann 2006) and have incorporated the subjective dimension in their theories. Examples abound, including Gregory Bateson’s (1958) ethos, Victor Turner's (1967) recognition of the orectic function of symbols and his notions of communitas and liminality, Meyer Fortes (1969) axiom of amity, Pierre Bourdieu's (1977) habitus, Sherry Ortner's (1984) practice theory, James Fernandez’s (1986) play of tropes, Paul Stoller's (1989) sensual ethnography, Thomas Csordas's (1990) ethnographic praxis, and Michael Herzfeld's (2005) social poetics and cultural intimacies.

We are both pleased and worried about the "turn" in anthropology and related fields to a relatively new focus on "affect", a term itself has multiple meanings and is difficult to define, identify and pinpoint (Massumi 1995: 88; Thrift 2004: 59; McElhinny 2010: 310; Seigworth and Gray 2010; Berlant and Greenwald 2012). "Affect” is both a noun and a transitive verb. As a transitive verb, "affect” entails a subject and an object or set of objects. As such it involves an 
interrelationship, one who affects and one who is affected. As a noun, "affect" has to do with senses and sensibilities and their relationship to the mind and to the body, aspects that are inseparable even as there is attempt to tease out the elements, to dissect feelings, desires, inclinations, intentions, and their effects on the level of the individual and on the level of the collective. Affect is something deeply interior but that also has outward manifestations. An individual with no facial expression, who does not gesture, whose tone of voice is monotoneseems dead—we might say that person "has no affect." Conversely, an individual who takes on exaggerated expression, gesture, tone of voice—seems overly vivid. We might say that person is "affected". The principles of collective affect may not be equivalent to those applied to individuals. Yet collectivities can and do have affect. The feelings that swell, the passion of the group, the vibrant intensity of the collective can be found in a political rally, religious gatherings, a music concert, a family get-together, sports events, and in mass celebrations. The organizing principle of mass celebrations can be any number of constructed identities—national, religious, gender, ethnic or racial, sexual orientation—or might be based on a common experience of oppression, violence, or struggle, of joy or of memory of actual or imagined events. Thus, affect as noun and verb has as much to do with senses and sensibilities of the collective unconscious and conscious and the body writ large — the body politic, the social and the cultural as it does with an individual's mind, body and emotion.

We are pleased by the focus on affect because it provides a space for highlighting, examining and privileging feelings, not just thought or the rational mind, and it emphasizes the part played by "structures of feeling" in social activity and interaction. Thus, the study of affect as both noun and verb suggests multiple dialectics: the individual and the collective, habitus and identity, emotion and relationship, consciousness and action. 
Yet, we are worried about this new turn for a number of reasons. First, we wonder if positioning “affect” as a new field of study requiring new theory, a new orientation, a new language, and new ethnographic ground will serve to erase what anthropology and other social sciences have long had to say about the dialectics of social life, its processes, dynamics, relationships, and formations on a field of action. Contemporary theoretical debates parsing differences between the anthropology of affect and of emotion seem to disregard that anthropologists have long been concerned with these issues, though not necessarily invoking the word used today.

For example, Richard and Rudnyckyj argue that the study of "affect” diverges from anthropological work on emotion (2009: 61). For them “affect suggests relations practised between individuals rather than experiences borne by sole individuals (ibid.),” purportedly the purview of “emotion”, a distinction we are not convinced is significant. Put another way, Bonnie McElhinny in her 2010 Annual Review article, “The Audacity of Affect," writes "Richard and Rudnyckyj note that current work on the 'economy of affect' differs from earlier feminist studies of 'emotion work' by focusing on 'the way in which subjects circulate within and are formed through affect, rather than the circulation of emotions between subjects’ (McElhinny 2010: 311312)," a distinction we find a bit artificial and too dismissive of the scholarly work that has come before. “The anthropology of emotions” is multidimensional, and as Lutz and White noted nearly 30 years ago, includes: “... being ‘about’ social relations; emotional meaning systems will reflect those relations and will, through emotion's constitution of social behavior, structure them” (Lutz and White 1986: 420).

Likewise, we worry that the positioning of “affect” studies as new will serve to erase the contributions of feminist scholars who have long understood the significance of "affect”-again, 
even if they didn’t necessarily use that term—-to signal that which must be examined, understood and altered, including the formation, circulation and reproduction of gendered subjectivities, sentiments, roles and duties, and the power dynamics at the center of social relations. Feminist activists and scholars have also long understood that the personal is the political and vice-versa, an understanding that refuses to relegate the private self in relation to others, or the affective or the experiential to a secondary role but sees these as central features and products of larger social, cultural, political and economic dynamics and conditions.

Related to these concerns is our worry that as scholars seek to construct, define and theorize a new field, they will lose themselves and the rest of us in impossible, arcane language, obscuring more than they illuminate. In The Affect Theory Reader, for example, a 2010 volume described on the back jacket as a "field-defining collection," the editors introduce the subject matter in an introduction titled "An Inventory of Shimmers," and explain "there is no single, generalizable theory of affect; not yet, and (thankfully) there never will be” (emphasis added). They also write, "If the individual essays of this volume are momentarily united, it is in their collectively singular attempts to address what transpires in the affective bloom-space of an everprocessual materiality (Seigworth and Gregg 2010: 9),” a terribly opaque sentence. In "Writing Shame," a lovely essay in the same volume, gender scholar Elspeth Probyn (2010) quotes Eve Sedgwick and Adam Frank to say, “...current treatises on affect tend to lack feeling...” and furthermore:

Affect is treated as a unitary category, with a unitary history and unitary politics. There is no theoretical room for any difference between, say, being amused, being disgusted, being ashamed, and being enraged. Genres are differentiated not in relation to the kind of affect they may evoke or generate but far more simply, by the presence or absence of 
some rarified substance called Affect. An abstract way of approaching affect and emotion places the writing itself in an uninterested relation to affect. This is a contradiction in terms—affects are inherently interested...How can you represent a sense of emotional and affective intensity if the feeling in question is generalized in the amorphous category of Affect? [Probyn 2010: 74]

Finally, we worry that the emphasis on "affect” will become an end in itself, moving us away from identifying and examining those powerful forces that set the conditions for making some forms of affect possible and others less likely or impossible. We believe this is what McElhinny means by the "intertwined and continuing gaps in the literature...noted early on by Lutz and White (1986), Abu Lughod and Lutz (1990), and Besnier (1990) in calling for more historical approaches... and further studies on hegemony, emotion, and social structure” (McElhinny 2010:312). Recent studies that situate affect historically, politically and economically include Masco’s (2008) look at the fear of nuclear annihilation induced in Cold War America, Muehlebach’s (2011) study of the manipulation of compassion in Italy's postFordist volunteer service sector, and Mazzarella’s (2010) exploration of Gandhi’s legacy, embodied in images of his ascetic body.

To the extent that the new focus and theoretical formulations advance understanding about social, cultural, psychological and political phenomena that have not before been examined and about which we have inadequate knowledge, it can be useful. To the extent that new theory offers a substantive, "real" distinction between "it" and related phenomena, it can have value. To the extent that putting affect "front stage in cultural descriptions and theory" enhances our understanding of its relationship to other aspects of social life and large-scale social forces that shape the social field of action, it offers great promise (Wolf 1990: 587). To the extent that its 
proponents can write about it in clear, comprehensible terms, we can evaluate whether or not we indeed need a new idiom—some might call it jargon— to talk about the empathy, sentiment, feelings, and emotions that have been found in the ethnographic literature from early on. Of course, there is always room for improvement as Andrew Beatty reminds readers in an essay on emotion, narrative, and the limits of ethnography: "ethnographic writing, by design, gets emotion wrong” (2010: 439). To the extent that the new "turn” can help us "get affect right,” it might bring us closer to what many consider as anthropology's purpose: to recognize our own humanity and that of others.

The articles in this special issue on affect and evocative ethnography discuss emotions, feelings, and sentiments in a variety of cultural contexts and encounters. The authors center emotion in their description and analysis of cultural behavior and are not afraid to privilege the role of feelings as central to understanding cultural meanings. Thus, in these articles "complex subjectivities" (Ortner 2005) are enlivened, and we see the ways in which they span the personal, interpersonal and transpersonal (Jackson 2012).

Edith Turner's opening article, "The Spirituality of Africa: The First Encounter," is a beautifully written evocation of her odyssey-like journey into anthropology. We travel with Turner as she leaves behind a class-ridden and exhausted post World War II England to join her loving husband in the field among the Ndembu in 1950s Northern Rhodesia (now Zambia). The excitement of the journey becomes a cathartic purging of past intellectual and emotional attachments, while opening up new theoretical insights and understandings. The physical and emotional journey becomes a metaphor for a parallel intellectual journey from positive empiricism of British structural functionalism to a spiritualized African sensibility in which 
feelings are front and center, influencing both her and her husband's intellectual and theoretical development, his work on symbolism and ritual process (Turner, V. 1967; 1974) and her work on communitas (Turner, E. 2012). Her description of Victor's tromping off one morning to the field, side-by-side with his informant, chortling, is a singular impression of love. Turner vividly describes the laying on of hands, and the transition of a girl to her future as a sexually mature woman during an initiation rite. The Grandfather spirit and emotions invoked in the Chihamba ritual become real to the participants, including the author, providing a necessary release for a community ravaged by disease and communal discord. For Turner, the inter-subjective feeling of joy rising from the experience, what Durkheim originally described and then discounted, is essential even as the full scope of sensations and their meanings are difficult to capture in words.

Considering the spiritual world as an affective realm is also the subject of Julia Cassaniti's article on Thai ghosts, "Intersubjective Affect and Embodied Emotion: Feeling the Thai Supernatural." As with the Ndembu, the spirits here are real with real effects. Cassaniti describes the intimate relationships and encounters her informants have with ghosts, and the emotions those spirits evoke in them, prompting specific human responses and actions. The Thai spirit world constitutes an affective cosmological space similar to that describe by Michael Jackson (2012) from his research in Sierra Leone, where the unconscious is construed as constituting a space out there in the world, exterior to the mind and body. Cassaniti points out that Thai religious practice is not all about feelings and ghostly encounters and sensations, but also about how individuals manage these feelings and discipline themselves to maintain a level of calm and composure. Cassaniti explores affect theory in order to reveal a similarity in the ways her Thai informants describe the supernatural world and Western scholars talk about affect. Her article suggests distinct ways that affect might be conceived, constructed and articulated in 
other cultures; in the Thai case, as supernatural or ghostly energies. Through the lens of the Thai supernatural she tries to parse emotion and affect and their relationship, shedding some light on affect theory.

Lucinda Carspecken's "The Unbounded Self: Peak Experiences and Border Crossings in Southern Indiana" describes four extreme cases of subjective, ecstatic experiences among neoPaganists in the United States. Her informants’ vivid experiences challenge conventional understandings of the self. They are cases of heightened sensory awareness, self-affirming euphoria, and disembodied mania. Here we reach, if not exceed the transpersonal end of the subjective arc with the blurring of the within and without, but with some sense of selfconsciousness maintained. For one informant, it was the exhilaration she experienced after having faced up to an abusive boyfriend and driving away from the small, hometown life she had been living. The experience affirmed for her the courageous choices she had made, enabling a new life. Here affect can be understood as a prompt to action, an example of Ortner's "subjective countercurrent" that provides space and agency for subalterns within a dominant discourse (Ortner 2005, 5; see also Herzfeld 2005). Another informant describes how ecstatic drumming and dancing helped peel away layers of the self and realize a deeper connection and identification with others and the world. The disembodied sensory experience of a third informant is described in mystical terms; he senses he is part of a big ball of light, feeling no pain, sorrow or suffering. The fourth informant experiences an acute sensory state of the world around him in which natural objects display auras. Such vision has a benign effect on his temperament that in turn has a similar contagious effect on those around him. In all, these are perceived by informants as life affirming experiences which ultimately bolster the subject's sense of self amidst often difficult, potentially life-draining circumstances. 
Nehemia Stern in his article, “’I Desire Sanctity”: Sanctity and Separateness among Jewish Religious Zionists in Israel/Palestine," discusses the theological construction of a religious affect and subjectivity called "sanctity" and practices associated with it among settlers in Israel and the Occupied West Bank. He compares different notions of sanctity, "immanent" and "transcendent", currently found in two different theological schools of Jewish thought. Both notions are the basis for settler identity, have implications for how settlers relate to and live in the world, and are inextricably linked to ideas of a Jewish state and nationhood. Believers in the notion of "immanent sanctity" see human activity in the world as the means to cultivate holiness; they can take some enjoyment in being in the world and pleasure in being "free" to mix with secular society. Believers in a "transcendent sanctity" see a much starker division between the profane and sacred that began the moment "God forces himself into 'exile"” to make room for Creation. In this rationale, building the Jewish state and establishing new settlements are the means to redeem Creation and bring God back out of exile. Followers of the transcendent theology keep themselves separate from the rest of society fearing the contagion of secular values and morality. Astonishingly both theologies have nothing to say about the plight of Palestinians and the future of Palestine-Israel. Piety does not extend to other religious communities in the region even as it forms the basis of a passionate but recalcitrant political movement that erases others in its midst, a silence that may come back to haunt the settlers. In this regard, it would be valuable for Stern to explore the intersections of collective affect with the orchestration of political emotion, which Berlant (2012) notes are different processes but "with lots of convergences and parallel tracks at the same time” (Berlant and Greenwald 2012: 77).

In "Valuing Affect: The Centrality of Emotion, Memory and Identity in Garage Sale Exchange,” Gretchen Herrmann takes us to a very different setting, the US garage sale. 
Herrmann describes "transfers of affectively-charged possessions" in the garage sale exchange. By definition, the garage sale happens in a very intimate, privatized space, inside or just outside the seller's home. The homeowner/seller welcomes outsiders into her home for the purpose of a transaction. The setting is emotionally charged, and the products are imbued with personal histories—some joyful, some unhappy, all of them poignant. Herrmann notes the garage sale venue allows for "a friendly, open informality that fosters affective exchanges among strangers...[uniting] shoppers and sellers in a unique affective way. The venue and the products themselves (used, with a history) seem to make a difference in setting the tone for the affective quality of the exchanges that result. Is it a stretch to suggest that the tone and quality of these exchanges also reflect a yearning for connection and community in our alienated world? We buy most new products in mass duplicated, brand name brick and mortar stores and shopping centers, or online where no human interaction at all is required. For her field sites, Hermann describes a closeness and a warmth that get forged very quickly between some sellers and buyers, an attachment that stands in stark contrast with the competitive, self-seeking individualism and materialism that dominates the contemporary marketplace. In the garage sale venue, sellers may want to generate revenue, but as Herrmann demonstrates, love, caring and generosity seem to prevail over crude financial profit. We wonder if this is always the case and if not, what might the exceptions mean? In some high-end suburbs of New York City, for example, garage sales can be sites of intense competition between antique dealers, consignment shop owners, and bargain hunters. We also wonder if there is any relationship between the habits of the consumer heart, trained as it has been by corporate marketers who spend billions of dollars devising ways to forge affective connections between consumers and products with images of "friendly, open informality"-and what happens in the garage sale venue. 
In “Sex Work, Heroin Injection, and HIV Risk in Tijuana: A Love Story,” Jennifer Syvertsen and Angela Bazzi bring us into the complicated triangle of Cindy, Beto and structural inequality where love and safety, danger and comfort, well-being and risk, and sickness and sorrow hang in uneasy relationship with poverty, marginalization, stigma and discrimination. Syvertsen and Bazzi do not invoke "affect theory" to frame the presentation of their data and analysis. Instead they link phenomenology and political economy; that is, they attend to the subjective, the experiential, the experience of consciousness and of feelings while never losing sight of structural relations and locations. In so doing, we believe Syvertsen and Bazzi "get affect right.” The anthropologists take us into Cindy and Beto's intimate world, their perceptions of it and the meanings they attach to their feelings, beliefs and behaviors. Their lives marked and constrained by structural violence, Cindy and Beto have crafted their own dangerous safe haven, an oxymoron that captures the nuances of a lifeworld caught in the web of forces beyond their control. Their lives reflect the "corporalization of grinding poverty" that has potential to sap political motivation (Nouvet 2014), a form of embodied social suffering that also affects health and well-being (Tapias 2006).

We anthropologists have probably set ourselves up for the impossible: to capture lived experience, emotionality and perception, small and large-scale interactivity, intimacy and sociality, power, politics and ever changing material conditions of social life without reducing one to the other-and portraying all of it in narrative form. By means of evocative ethnography, this special collection on the anthropology of affect seeks to take up the challenge and fearlessly embrace the complexities.

\section{ACKNOWLEDGEMENTS}

This special issue originated in a panel on the anthropology of affect at the 2012 Annual Meeting of American Anthropological Association in San Francisco, organized by Ian Skoggard with the 
assistance of Melissa Beske. We would like to thank the panel discussants, Edith Turner and Alisse Waterston, and the anonymous journal reviewers, who all provided incisive commentary. We also thank the journal editors, Peter Benson and Rebecca Lester, for their support and help in shepherding the papers through the review process.

\section{REFERENCES CITED}

Abu-Lughod Lila and Catherine Lutz

1990 Introduction: Emotion, Discourse and the Politics of Everyday Life. In Language and the Politics of Emotion. Catherine Lutz and Lila Abu-Lughod, eds. Pp.1-23. Cambridge, UK: Cambridge University Press..

Ahmed, Sara

2004 Affective Economies. Social Text 22:118-139.

Beatty, Andrew.

2010 How Did It Feel For You? Emotion, Narrative, and the Limits of Ethnography. American Anthropologist 112(3):430-443.

Berlant, Lauren

2008 Female Complaint: The Unfinished Business of Sentimentality in American Culture. Durham, NC: Duke University Press.

Berlant, Lauren and Jordan Greenwald

2012 Affect in the End of Times: A Conversation with Lauren Berlant. Qui Parle: Critical Humanities and Social Sciences 20(2): 71-89.

Besnier, Niko

1990 Language and Affect. Annual Review of Anthropology 19:419-451.

Bourdieu, Pierre

1977 Outline of a Theory of Practice. New York: Cambridge University Press.

Brown, Michael E.

2014 The Concept of the Social in Uniting the Humanities and Social Sciences. Philadelphia: Temple University Press.

Charland, Louis C.

2001 Review: In Defence of "Emotion". Canadian Journal of Philosophy 31(1):133-154.

Csordas, Thomas J.

1990 Embodiment as a Paradigm for Anthropology. Ethos. 18(1):5-47.

Dalgleish, Tim 
2004 The Emotional Brain. Nature Reviews Neuroscience 5(7):583-589.

Damasio, Antonio

1995 Descartes' Error: Emotion, Reason, and the Human Body. New York: Avon.

Durkheim, Emile

1965 [1915] The Elementary Forms of Religious Life. New York: The Free Press.

Fernandez, James W.

1986 Persuasions and Performances: The Play of Tropes in Culture. Bloomington, IN: Indiana University Press.

Fortes, Meter

2006 [1969] Kinship and the Social Order: The Legacy of Lewis Henry Morgan. New Brunswick, NJ: Aldine Transaction.

Goldschmidt, Walter

2006 Bridge to Humanity: How Affect Hunger Trumps the Selfish Gene. New York: Oxford University Press.

Herzfeld, Michael

2005 Cultural Intimacy: Social Poetics in the Nation-State. New York: Routledge.

Jackson, Michael

2012 Commentary: The Complementarity of Intrapsychic and Intersubjective Dimensions of Social Reality. Ethos 40(1):113-118.

Leavitt, John

1995 Meaning and Feeling in the Anthropology of Emotions. American Ethnologist 23(3):514-539.

Luhrmann, Tanya

2006 Subjectivity. Anthropological Theory 6:345-361.

Lutz, Catherine and Geoffrey M. White

1986 The Anthropology of Emotions. Annual Review of Anthropology 15:405-436.

Masco, Joseph

2008 "Survival is Your Business": Engineering Ruins and Affect in Nuclear America. Cultural Anthropology 23(2):361-398.

Massumi, Brian

1995 The Autonomy of Affect. Cultural Critique 31:83-109.

Mazzarella, William 
2010 Branding the Mahatma: The Untimely Provocation of Gandhian Publicity. Cultural Anthropology 25(1):1-39.

McElhinny, Bonnie

2010 The Audacity of Affect: Gender, Race, and History in Linguistic Accounts of Legitimacy and Belonging. Annual Review of Anthropology 39:309-328.

Muehlebach, Andrea

2011 On Affective Labor in Post-Fordist Italy. Cultural Anthropology 26(1):59-82.

Nouvet, Elysée

2014 Some Carry On, Some Stay in Bed: (In)convenient Affect and Agency in Neoliberal Nicaragua. Cultural Anthropology 29(1):80-102.

Ortner, Sherry

2005 Subjectivity and Cultural Critique. Anthropological Theory 5:31-52.

Probyn, Elspeth

2010 Writing Shame. In Affect Theory Reader. Melissa Gregg and Gregory J. Seigworth, eds. Pp. 71-89. Durham, NC: Duke University Press.

Richard, Analiese and Daromir Rudnycky

2009 Economies of Affect. Journal of the Royal Anthropological Institute 15:57-77.

Seigworth, Gregory J and Melissa Gregg

2010 An Inventory of Shimmers. In Affect Theory Reader. Melissa Gregg and Gregory J. Seigworth, eds. Pp. 1-25. Durham, NC: Duke University Press.

Stewart, Kathleen

2007 Ordinary Affects. Durham, NC: Duke University Press.

Stoller, Paul

1989 The Taste of Ethnographic Things: The Senses in Anthropology. Philadelphia: University of Pennsylvania Press.

2005 The Presence of the Ethnographic Present: Some Brief Comments on Loïc Wacquant's Body and Soul. Qualitative Sociology 28(2): 197-199.

2007 Ethnography/Memoir/Imagination/Story. Anthropology and Humanism 32(2):178-191.

Tapias, Maria

2006 Emotions and the Intergenerational Embodiment of Social Suffering in Rural Bolivia. Medical Anthropology Quarterly 20(3):399-415.

Thrift, Nigel 
2004 Intensities of Feeling: Towards a Spatial Politics of Affect. Geograliska Annaler 86:57-78

Turner Edith

2012 Communitas: The Anthropology of Collective Joy. New York: Palgrave Macmillan.

Turner, Victor

1967 The Forest of Symbols: Aspects of Ndembu Ritual. Ithaca, NY: Cornell University Press.

1974 Dramas, Fields, and Metaphors: Symbolic Action in Human Society. Ithaca, NY: Cornell University Press.

Wolf, Eric R.

1990 Distinguished Lecture: Facing Power: Old Insights, New Questions. American Anthropologist 92 (5): 586-96.

Zajonc, Robert B.

1980 Feelings and Thinking: Preferences Need No Inferences. American Psychologist 35(2):151-175. 